\title{
A randomized trial of Plasma-Lyte $A$ and $0.9 \%$ sodium chloride in acute pediatric gastroenteritis
}

Coburn H. Allen ${ }^{*}$, Ran D. Goldman², Seema Bhatt ${ }^{3}$, Harold K. Simon ${ }^{4}$, Marc H. Gorelick ${ }^{5}$, Philip R. Spandorfer ${ }^{6}$, David M. Spiro ${ }^{7}$, Sharon E. Mace ${ }^{8}$, David W. Johnson ${ }^{9}$, Eric A. Higginbotham ${ }^{1}$, Hongyan Du ${ }^{10}$, Brendan J. Smyth ${ }^{11}$, Carol R. Schermer ${ }^{10}$ and Stuart L. Goldstein ${ }^{3}$

\begin{abstract}
Background: Compare the efficacy and safety of Plasma-Lyte A (PLA) versus $0.9 \%$ sodium chloride (NaCl) intravenous (IV) fluid replacement in children with moderate to severe dehydration secondary to acute gastroenteritis (AGE).
\end{abstract}

Methods: Prospective, randomized, double-blind study conducted at eight pediatric emergency departments (EDs) in the US and Canada (NCT\#01234883). The primary outcome measure was serum bicarbonate level at $4 \mathrm{~h}$. Secondary outcomes included safety and tolerability. The hypothesis was that PLA would be superior to $0.9 \%$ $\mathrm{NaCl}$ in improvement of 4 -h bicarbonate. Patients $(n=100)$ aged $\geq 6$ months to $<11$ years with AGE-induced moderate-to-severe dehydration were enrolled. Patients with a baseline bicarbonate level $\leq 22 \mathrm{mEq} / \mathrm{L}$ formed the modified intent to treat ( $\mathrm{mlTT}$ ) group.

Results: At baseline, the treatment groups were comparable except that the PLA group was older. At hour 4, the PLA group had greater increases in serum bicarbonate from baseline than did the $0.9 \% \mathrm{NaCl}$ group (mean \pm SD at 4 h: $18 \pm 3.74$ vs $18.0 \pm 3.67$; change from baseline of 1.6 and 0.0 , respectively; $P=.004$ ). Both treatment groups received similar fluid volumes. The PLA group had less abdominal pain and better dehydration scores at hour 2 (both $P=.03$ ) but not at hour $4(P=0.15$ and 0.08 , respectively). No patient experienced clinically relevant worsening of laboratory findings or physical examination, and hospital admission rates were similar. One patient in each treatment group developed hyponatremia. Four patients developed hyperkalemia (PLA:1, $0.9 \%$ NaCl:3).

Conclusion: In comparison with $0.9 \% \mathrm{NaCl}$, PLA for rehydration in children with AGE was well tolerated and led to more rapid improvement in serum bicarbonate and dehydration score.

Trial registration: NCT\#01234883 (Registration Date: November 3, 2010).

Keywords: Balanced fluid therapy, Dehydration, Hyperchloremic metabolic acidosis, Plasma-Lyte A, Rehydration, Gastroenteritis

\footnotetext{
* Correspondence: challen@seton.org

${ }^{1}$ Department of Pediatrics, Dell Medical School at University of Texas at

Austin, 4900 Mueller Blvd, Austin, TX 78746, USA

Full list of author information is available at the end of the article
}

\section{Ciomed Central}

(C) 2016 The Author(s). Open Access This article is distributed under the terms of the Creative Commons Attribution 4.0 International License (http://creativecommons.org/licenses/by/4.0/), which permits unrestricted use, distribution, and reproduction in any medium, provided you give appropriate credit to the original author(s) and the source, provide a link to the Creative Commons license, and indicate if changes were made. The Creative Commons Public Domain Dedication waiver (http://creativecommons.org/publicdomain/zero/1.0/) applies to the data made available in this article, unless otherwise stated. 


\section{Background}

Acute gastroenteritis (AGE) complicated by dehydration remains a major cause of childhood morbidity and mortality, requiring significant healthcare expenditure worldwide [1-3]. Approximately 179 million cases of AGE occur in the US each year [4-6]. Despite a decrease in positive laboratory diagnoses of AGE, likely attributable to rotavirus vaccination availability since 2006 [7], substantial disease remains. The fluid loss associated with AGE not only causes dehydration, but can lead to metabolic acidosis and electrolyte disturbances $[1,6,8,9]$.

Intravenous fluid therapy (IVT) is the mainstay of treatment for severe pediatric dehydration, and the requirement for continued IVT is the leading indication for hospitalization. However, recommendations for IVT are poorly standardized, and significant controversy exists as to the optimal fluid for use in children $[10,11]$. In general, isotonic fluids are advised for acute rehydration with the most commonly administered fluids being 0.9 \% sodium chloride $(\mathrm{NaCl})$ and Lactated Ringer's (LR) solution [12]. However, $0.9 \% \mathrm{NaCl}$, which contains a supraphysiologic chloride concentration, can induce hyperchloremic metabolic acidosis ( $\mathrm{HCA}$ ), which can exacerbate the low serum bicarbonate levels often associated with diarrhea and poor perfusion from dehydration [13]. To prevent HCA, clinicians use LR, but concerns of hyponatremia due to low sodium concentration limit its use [12]. Thus, there is a substantial need to further evaluate alternative isotonic crystalloids as a treatment for AGE [10].

Plasma-Lyte A (PLA, Baxter Healthcare, Deerfield, IL), a balanced isotonic crystalloid, contains physiologic sodium, chloride, potassium, magnesium, and bicarbonate precursors in mEq/L: $\mathrm{Na} \mathrm{140,} \mathrm{K} \mathrm{5,} \mathrm{Cl} \mathrm{98,} \mathrm{Mg} \mathrm{3,} \mathrm{Acetate}$ 27 , and gluconate $23, \mathrm{pH} 7.4$ ). It is utilized as a source of water and electrolytes or as an alkalinizing agent. Several studies in adults have reported a reduction in the incidence of hyperchloremia and metabolic acidosis with balanced solutions (eg, LR and PLA) over $0.9 \% \mathrm{NaCl}$ [14-16]. The osmolarity of Plasma-Lyte A is 294 mOs$\mathrm{mol} / \mathrm{L}$, within the pediatric reference range [17]. Of note, isotonic Plasma-Lyte has different naming conventions around the globe and hence different publications may refer to Plasmalyte A, Plasmalyte, or Plasmalyte 148. In the Unites States, there are 2 naming formulations which are identical in ionic composition but which differ in solution pH: Plasma-Lyte A (used here) which has a pH of 7.4 and Plasma-lyte 148 which has a $\mathrm{pH}$ of 5.5.

Plasma-Lyte A has not previously been studied specifically in the pediatric population. In addition to the physiologic chloride level, PLA contains acetate and gluconate, which serve as buffering agents. It may be preferred for children with AGE because it replaces water and electrolytes lost due to diarrhea and vomiting as well as bicarbonate lost in stool. PLA has the potential to reverse the acidosis that may contribute to the physical symptoms of nausea, vomiting, diarrhea, and abdominal pain $[18,19]$.

The hypothesis of this study was that PLA would be superior to $0.9 \% \mathrm{NaCl}$ in improvement of 4-h bicarbonate level and result in faster resolution of clinical signs and symptoms in children with AGE and dehydration.

\section{Methods}

This prospective, randomized, triple-blind, companysponsored, active-controlled study was conducted at 8 pediatric emergency departments (ED) in the US and Canada (NCT\#01234883). Institutional ethics approval was obtained from each institution (Additional file 1: Table S1), and written informed consent was obtained from the parent/legal guardian of all children before randomization. Safety data were periodically monitored by an independent consultant (pediatric nephrologist, SLG) who was not involved in patient recruitment or management.

Patients $\geq 6$ months to $<11$ years of age were eligible for enrollment if they presented to the ED with moderateto-severe dehydration due to AGE, defined as $\geq 3$ episodes of diarrhea or nonbilious vomiting within the previous $24 \mathrm{~h}$ and a Gorelick dehydration score $\geq 4$ [20]. Screened patients had blood drawn for serum chemistry. A prerandomization fluid bolus of $\leq 20 \mathrm{~mL} / \mathrm{kg}$ in the $4 \mathrm{~h}$ prior to enrollment was permitted. Exclusion criteria included AGE that did not require IVT per clinicians' judgment, chronic health conditions such as renal failure affecting the ability to tolerate fluids or those that result in electrolyte abnormalities, or the use of prohibited medications (eg, antacids/anti-diarrhea or systemic corticosteroids within 24 or $72 \mathrm{~h}$ prior to presentation, respectively).

During the prestudy period, all patients received routine care, and oral rehydration therapy and IVT per clinician judgment. Screening included review of inclusion/exclusion criteria, complete medical history and physical exam, Gorelick score, abdominal pain assessment, and assessment of volume and type of prestudy IVT.

Concealed treatment allocation was via an Interactive Voice Recognition System/Interactive Web-based System. Eligible patients were randomly assigned in a 1:1 ratio to receive concealed bolus therapy with PLA (Multiple Electrolyte Injection, Type 1) or $0.9 \% \mathrm{NaCl}$. Following randomization, hour 0 was defined as the beginning of infusion of the first bolus of blinded study treatment. Patients were assessed at baseline, hour $4( \pm 1)$, and $48 \pm$ $6 \mathrm{~h}$. The study treatment period was for up to $8 \mathrm{~h}$. If the patient continued to require IVT beyond the study treatment period, the clinician ordered standard-of-care rehydration IVT. The safety follow-up period was defined from the end of the last blinded study bolus to $48 \pm 6 \mathrm{~h}$. The protocol recommended $20 \mathrm{~mL} / \mathrm{kg}$ for the first study 
treatment IV bolus, but the ordered dose was left to provider discretion [21].

The primary outcome was the change in venous serum bicarbonate, as measure by total carbon dioxide by clinical chemistry automated analyzers via local laboratories, between baseline (hour 0 ) and hour 4 . Secondary outcomes included assessments of the Gorelick score; the Baxter Animated Retching Face (BARF) [22] score for nausea/vomiting; pain (FLACC scale for ages six months to three years, FACES scale for ages 3-11 years); volume and duration of IVT; time to clinical rehydration, and length of stay in the ED. Safety assessments included physical examinations, laboratory assessments, and any reported or observed adverse events (AEs). At the safety follow-up, information was obtained regarding AEs, unplanned return visits, and hospital admission.

The intent-to-treat (ITT) population included all patients who were randomized to receive study treatment and was used to assess safety. For the primary and secondary outcomes, a modified intent-to-treat (mITT) analysis was used to focus on only those patients with a baseline serum bicarbonate level $\leq 22 \mathrm{mEq} / \mathrm{L}$. This was necessary in order to allow clinicians to initiate the first study treatment bolus per standard of care prior to receipt of initial laboratory test results. However, only patients with baseline serum bicarbonate level $\leq 22 \mathrm{mEq} / \mathrm{L}$ continued study treatment in $10-$ to- $20 \mathrm{~mL} / \mathrm{kg}$ allotments until clinical rehydration was achieved or hour 8 transpired, whichever occurred first and was considered the "end of study" treatment. Enrolled patients with baseline bicarbonate $>22 \mathrm{mEq} / \mathrm{L}$ had the study infusion stopped and were considered "early treatment release (ETR)." They did not undergo 4-h laboratory testing but were followed for safety parameters.
Sample size determination was made assuming a $25 \%$ coefficient of variation and a $15 \%$ difference between PLA and $0.9 \% \mathrm{NaCl}$ for serum bicarbonate level, following a log-normal distribution. A sample size of 80 evaluable mITT patients (40 per treatment group) had a power of $80 \%$ to detect such a difference with a 1-sided alpha of 0.05 . Planned enrollment for this study was approximately 112 subjects (56 subjects per treatment group to ensure 40 evaluable mITT subjects per treatment group), with an estimated $30 \%$ attrition rate. The superiority of PLA in maintaining the baseline serum bicarbonate levels was established if the one-sided $95 \%$ lower limit of the change from hour 0 to hour 4 geometric mean ratio of test/control was greater than one. Stratified analyses by age range and severity of baseline serum bicarbonate level for the primary outcome were planned a priori. For continuous efficacy and safety variables, descriptive summary statistics were provided by treatment group and time, whereas between-treatment comparisons at the post-baseline visits were performed with respect to difference or geometric mean ratio from baseline. All data are reported, but no statistical comparisons were performed for groups with $<10$ subjects. SAS procedures MIXED, GENMOD, and LOGISTIC (SAS OnlineDoc ${ }^{\circ}$, SAS Institute Inc., Cary, $\mathrm{NC})$ were used to carry out all analyses. No interim analyses were planned or performed.

\section{Results}

Patient disposition is shown in Fig. 1. The study enrollment period was from January 20, 2011, through February 4, 2013, during which approximately 2,669 patients were prescreened for study inclusion. The exact number of patients seen is an estimate, due to different screening

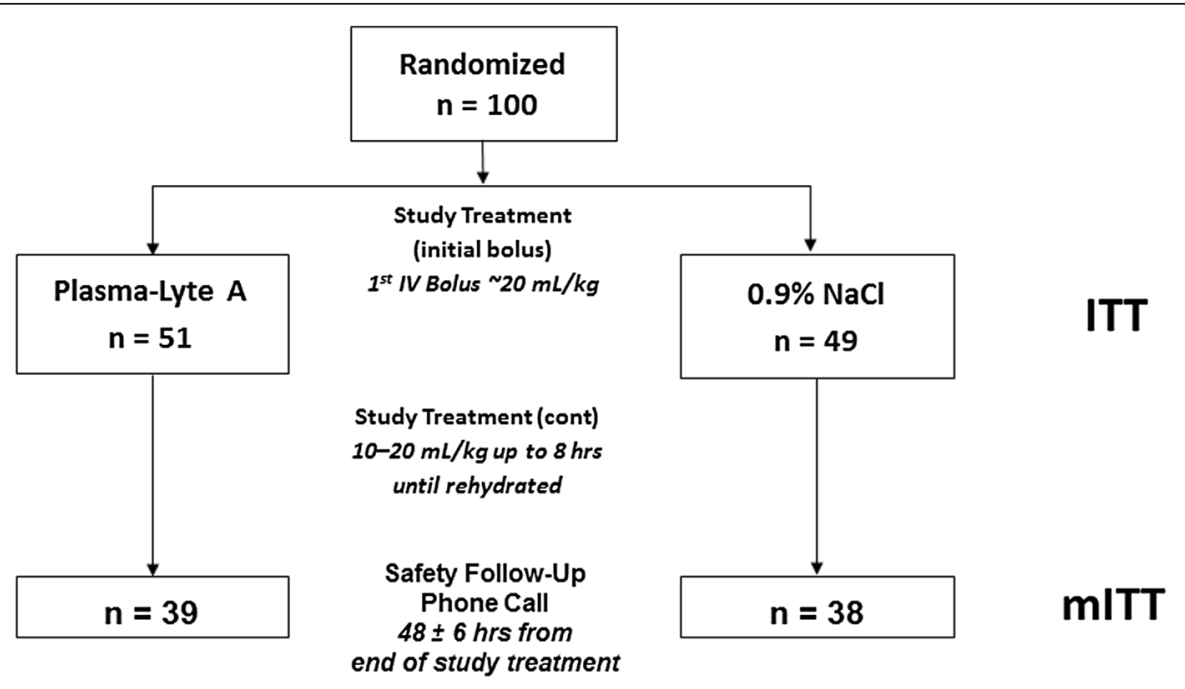

The modified intent-to-treat (mITT) analysis set included all randomized patients who had a baseline bicarbonate level $\leq 22 \mathrm{mEq} / \mathrm{L}$.

Fig. 1 Patient disposition 
processes between the centers. The study was stopped early due to slow recruitment after 100 patients were enrolled with 77 evaluable mITT subjects. The ITT group was formed by 100 patients who were randomized to receive either PLA $(n=51)$ or $0.9 \% \mathrm{NaCl}(n=49)$. ETR occurred in 23 patients due to baseline bicarbonate $>22 \mathrm{mEq} / \mathrm{L}$. There were 77 patients (PLA: 39; $0.9 \% \mathrm{NaCl}: 38$ ) in the mITT group for assessment of the primary outcome.

\section{Pre-study Treatment Period Comparison}

Baseline comparison of the mITT treatment groups is presented in Table 1. Of note, patients in the PLA group were older. Both groups exhibited similar Gorelick dehydration scores, as well as similar FLACC, FACES, and BARF scores. In addition, both groups had similar weightbased fluid administration prior to receipt of study fluid (PLA: $17.98 \pm 11.17 \mathrm{ml} / \mathrm{kg}$ vs $0.9 \% \mathrm{NaCl}: 15.38 \pm 6.55 \mathrm{ml} /$ kg; Additional file 1: Table S2).

\section{Treatment and outcomes}

There were no significant differences in volume, duration of fluid administration, or maintenance IVT between groups. The number of boluses was 1.9 for both groups,

Table 1 Baseline clinical and biochemical characteristics (mITT population)

\begin{tabular}{|c|c|c|c|}
\hline & \multirow{2}{*}{$\begin{array}{l}\text { Plasma-Lyte A } \\
n=39\end{array}$} & \multirow{2}{*}{$\begin{array}{l}0.9 \% \mathrm{NaCl} \\
n=38\end{array}$} \\
\hline & & & \\
\hline \multicolumn{2}{|c|}{ Age $^{*}$, months, mean } & 45.9 & 34.2 \\
\hline \multirow[t]{3}{*}{ Age group, n (\%) } & $\geq 6$ months to $\leq 2$ years & $8(21)$ & $20(53)$ \\
\hline & $>2$ to $\leq 5$ years & $21(54)$ & $11(29)$ \\
\hline & $>5$ to $<11$ years & $10(26)$ & $7(18)$ \\
\hline \multicolumn{2}{|l|}{ Weight*, kg } & $15.8 \pm 5.18$ & $13.5 \pm 6.80$ \\
\hline \multicolumn{2}{|l|}{ Vomiting episodes } & $8.9 \pm 8.53$ & $6.1 \pm 5.92$ \\
\hline \multicolumn{2}{|l|}{ Diarrhea episodes } & $4.8 \pm 4.77$ & $6.8 \pm 6.77$ \\
\hline \multicolumn{2}{|c|}{ Capillary refill time*, seconds } & $3.3 \pm 0.50$ & $2.8 \pm 0.26$ \\
\hline \multicolumn{2}{|l|}{ Bicarbonate, mEq/L } & $16.9 \pm 3.51$ & $17.8 \pm 2.82$ \\
\hline \multicolumn{2}{|l|}{ Sodium, mEq/L } & $137.0 \pm 4.07$ & $136.9 \pm 2.93$ \\
\hline \multicolumn{2}{|l|}{ Potassium, mEq/L } & $4.4 \pm 0.80$ & $4.2 \pm 0.67$ \\
\hline \multicolumn{2}{|l|}{ Chloride, $\mathrm{mEq} / \mathrm{L}$} & $103.0 \pm 4.74$ & $103.5 \pm 4.19$ \\
\hline \multicolumn{2}{|l|}{$\mathrm{BUN}, \mathrm{mg} / \mathrm{dL}$} & $16.5 \pm 7.17$ & $14.6 \pm 6.33$ \\
\hline \multicolumn{2}{|l|}{ Creatinine*, mg/dL } & $0.43 \pm 0.13$ & $0.37 \pm 0.10$ \\
\hline \multicolumn{2}{|l|}{ Glucose, mg/dL } & $70.3 \pm 21.26$ & $74.4 \pm 21.62$ \\
\hline \multicolumn{2}{|c|}{ Gorelick dehydration scale, median (IQR) } & $5(5-6)$ & $5(5-6)$ \\
\hline \multicolumn{2}{|l|}{ Ondansetron } & $36(92)$ & $29(76)$ \\
\hline \multicolumn{2}{|l|}{ All analgesics ${ }^{a}$} & $25(64)$ & $23(61)$ \\
\hline
\end{tabular}

BUN blood urea nitrogen, IQR interquartile range

All data are presented as mean \pm standard deviation unless otherwise indicated

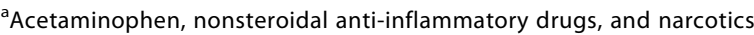
administered orally and/or by intravenous infusion

${ }^{*} P<0.05$ PLA vs $0.9 \% \mathrm{NaCl}$ dose of study treatment was $38.4 \mathrm{~mL} / \mathrm{kg}$ vs $39.6 \mathrm{~mL} / \mathrm{kg}$, duration of administration was $104.3 \mathrm{~min}$ vs $93.7 \mathrm{~min}$ and maintenance fluid was 12.2 vs $12.3 \mathrm{~mL} / \mathrm{kg}$ PLA vs $0.9 \%$ $\mathrm{NaCl}$ respectively, all $P>.05$. Twelve patients in the PLA group received concomitant maintenance IV fluid vs 11 in the $0.9 \% \mathrm{NaCl}$ group.

Outcome comparisons between the two groups are presented in Table 2. Patients receiving PLA demonstrated significantly greater increase in serum bicarbonate levels from baseline to hour 4 compared with patients receiving $0.9 \% \mathrm{NaCl}$. When stratified by bicarbonate level severity, PLA showed superiority over $0.9 \% \mathrm{NaCl}$ treatment for bicarbonate ranges $\geq 12$ to 16 . Although PLA patients in the $>16$ to $22 \mathrm{mEq} / \mathrm{L}$ bicarbonate range had a statistically significant increase in serum bicarbonate levels $(P<.05)$, the increase in the PLA group was not significantly different from the $0.9 \% \mathrm{NaCl}$ group $(P=.11)$ for this bicarbonate range. None of the patients receiving $0.9 \% \mathrm{NaCl}$ had baseline serum bicarbonate level $<12 \mathrm{mEq} / \mathrm{L}$. The three patients with severe acidosis who received PLA demonstrated a mean improvement in serum bicarbonate level from $9.3 \pm 0.6 \mathrm{mEq} / \mathrm{L}$ to $14.3 \pm 4.2 \mathrm{mEq} / \mathrm{L}$.

Comparison by age strata demonstrated PLA superiority for the $>2$ years to $\leq 5$ years age range (mean 17.16 to $18.31 ; P<.05)$. Although the $>5$ years to $<11$ years age range had a significant increase in serum bicarbonate level for PLA patients $(P<.05)$, superiority over $0.9 \% \mathrm{NaCl}$ was not calculated due to the small number of older subjects in the $0.9 \% \mathrm{NaCl}$ group. Patients receiving PLA demonstrated significant improvements in clinical status as measured by the hour 2 Gorelick score and FLACC pain scales. Patients in the PLA group had improvement in BARF scores from baseline to hour 2 (mean change $-3.6 \pm 5.1 ; P=.005$ ) and hour 4 (mean change $-4.8 \pm 3.97 ; P=.005)$. Patients in the $0.9 \% \mathrm{NaCl}$ group did not show similar BARF score improvements at hour 2 (mean change- $2.1 \pm 4.0 ; P=.08$ ) but did at hour 4 (mean change $-2.9 \pm 3.88 ; P=.02$ ). However, between-group BARF scores were not significant. No other differences in secondary outcome measures were observed.

\section{Safety outcomes}

The shift in potassium and sodium levels from baseline to hour 4 is presented in Figs. 2 and 3. There were no episodes of hyponatremia $(<130 \mathrm{mEq} / \mathrm{L})$ or hypernatremia $(>155 \mathrm{mEq} / \mathrm{L})$ in either group. Some patients in each group presented with hyponatremia that was also documented at hour 4 (PLA: 8/13; $0.9 \% \mathrm{NaCl}: 4 / 8$ ), and one patient in each group developed mild hyponatremia (131-135 mEq/L). Hypokalemia $(<3.5 \mathrm{mEq} / \mathrm{L}$ for ages $\geq 6$ months to $\leq 2$ years and $<3.0 \mathrm{mEq} / \mathrm{L}$ for ages $2-11$ years) and hyperkalemia ( $>5.6 \mathrm{mEq} / \mathrm{L}$ for ages $\geq 6$ months 
Table 2 Primary and secondary outcomes (mITT population)

\begin{tabular}{|c|c|c|c|}
\hline \multirow{3}{*}{$\overline{\text { Bicarbonate }<23 \mathrm{mEq} / \mathrm{L}}$} & \multirow{2}{*}{$\begin{array}{l}\text { Plasma-Lyte A } \\
n=39\end{array}$} & \multirow{2}{*}{$\begin{array}{l}0.9 \% \mathrm{NaCl} \\
n=38\end{array}$} & \multirow[t]{2}{*}{$P$ value } \\
\hline & & & \\
\hline & & & \\
\hline Baseline (hour 0) & $16.9 \pm 3.51$ & $17.8 \pm 2.82$ & .004 \\
\hline Hour 4 & $18.5 \pm 3.74$ & $18.0 \pm 3.67$ & \\
\hline \multicolumn{4}{|l|}{ Bicarbonate $<12 \mathrm{mEq} / \mathrm{L}$} \\
\hline Baseline (hour 0) (n) & $9.3 \pm 0.58(3)$ & $-(0)$ & $N A^{b}$ \\
\hline Hour 4 (n) & $14.3 \pm 4.16$ & $-(0)$ & \\
\hline \multicolumn{4}{|c|}{ Bicarbonate $\geq 12-16 \mathrm{mEq} / \mathrm{L}$} \\
\hline Baseline (hour 0) (n) & $14.5 \pm 1.34(13)$ & $14.6 \pm 1.29(13)$ & .04 \\
\hline Hour 4 (n) & $16.1 \pm 2.28(12)$ & $14.7 \pm 2.90(11)$ & \\
\hline \multicolumn{4}{|c|}{ Bicarbonate $>16-22 \mathrm{mEq} / \mathrm{L}$} \\
\hline Baseline (hour 0) (n) & $19.23 \pm 1.86(23)$ & $19.51 \pm 1.68(25)$ & .11 \\
\hline Hour 4 (n) & $20.35 \pm 3.18(22)$ & $19.53 \pm 2.95(24)$ & \\
\hline \multicolumn{4}{|l|}{ Chloride, $\mathrm{mmol} / \mathrm{L}$} \\
\hline Baseline & $103.03 \pm 4.74$ & $103.53 \pm 4.19$ & $<0.001$ \\
\hline Hour 4 & $104.49 \pm 3.18$ & $108.51 \pm 4.87$ & \\
\hline \multicolumn{4}{|l|}{ Gorelick dehydration scale } \\
\hline Baseline (hour 0) & $5.2 \pm 0.93$ & $5.3 \pm 1.11$ & .03 \\
\hline Hour 2 & $2.0 \pm 1.45$ & $2.8 \pm 1.74$ & \\
\hline Hour 4 & $0.81 \pm 0.84$ & $1.41 \pm 1.08$ & .08 \\
\hline \multicolumn{4}{|l|}{ FLACC pain scale } \\
\hline Baseline (Hour 0) & $2.0 \pm 1.91$ & $1.7 \pm 2.00$ & .03 \\
\hline Hour 2 & $0.6 \pm 0.98$ & $1.7 \pm 2.59$ & \\
\hline Hour 4 & $1.44 \pm 2.18$ & $0.68 \pm 1.35$ & .15 \\
\hline \multicolumn{4}{|l|}{ FACES pain scale } \\
\hline Baseline (Hour 0) & $2.3 \pm 1.86$ & $3.2 \pm 1.90$ & .31 \\
\hline Hour 2 & $1.1 \pm 1.55$ & $1.9 \pm 1.60$ & \\
\hline Hour 4 & $0.37 \pm 0.60$ & $1.11 \pm 1.54$ & NA \\
\hline \multicolumn{4}{|l|}{ BARF Scale } \\
\hline Baseline (Hour 0) & $5.10 \pm 4.02$ & $4.43 \pm 3.86$ & .27 \\
\hline Hour 2 & $1.5 \pm 3.10$ & $2.00 \pm 2.58$ & .55 \\
\hline Hour 4 & $0.3 \pm 0.98$ & $1.23 \pm 2.24$ & .12 \\
\hline Time to Rehydration ${ }^{\mathrm{a}}, \mathrm{h}$ & $6.1 \pm 1.75$ & $7.0 \pm 2.7$ & .13 \\
\hline Hospitalized, n (\%) & $12(31)$ & $11(29)$ & .86 \\
\hline
\end{tabular}

BARF, Baxter animated retching faces; FLACC, face, legs, activity, cry, consolability pain assessment scale for children

All data are presented as mean \pm standard deviation unless otherwise indicated

${ }^{a}$ Rehydration was defined as the time the clinician determined no further bolus fluid therapy was indicated

${ }^{b}$ Not available due to sample size $(n<10)$

to $\leq 2$ years and $>5.5 \mathrm{mEq} / \mathrm{L}$ for ages $2-11$ years) were both assessed. Two patients in the PLA group vs 6 in the $0.9 \% \mathrm{NaCl}$ group became hypokalemic at hour 4 . Four patients in the study developed hyperkalemia (PLA: $1 / 39$ vs $0.9 \% \mathrm{NaCl}: 3 / 38$ ) by hour 4 . All samples showing hyperkalemia demonstrated hemolysis, all of which were deemed clinically insignificant by the investigators.

\section{Discussion}

This prospective, randomized, triple-blind, multicenter trial comparing PLA to $0.9 \% \mathrm{NaCl}$ in children with dehydration secondary to AGE determined that PLA was superior to $0.9 \% \mathrm{NaCl}$ for improving the metabolic acidosis (change from baseline in bicarbonate of $1.6 \mathrm{mEq} / \mathrm{L}$ for PLA vs $0.0 \mathrm{mEq} / \mathrm{L}$ for $0.9 \% \mathrm{NaCl}$ ) despite comparable initial 


\section{Plasma-Lyte A \\ $\mathrm{n}=39$}

Baseline

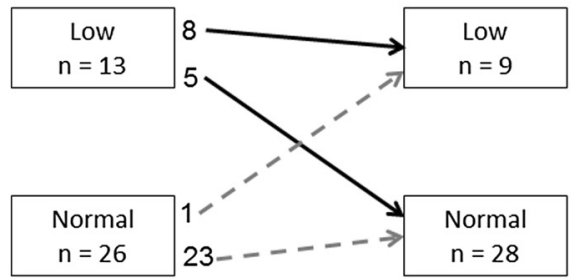

$0.9 \% \mathrm{NaCl}$

$\mathrm{n}=38$

Baseline

Hour 4

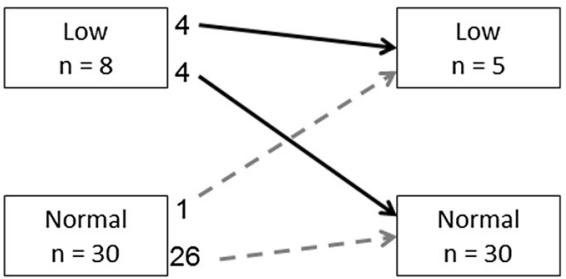

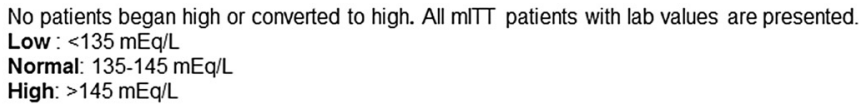

Fig. 2 Change in sodium levels from baseline to hour 4

serum bicarbonate levels and comparable volumes of IVT. In addition to acidosis, pain as assessed by the FLACC scale, and dehydration score significantly improved at hour 2 in patients receiving PLA. The clinical significance of the improved dehydration scores at hour 2 is unclear as the dehydration scores were not significantly improved at hour 4 in patients receiving PLA. It may be that once the intravascular fluids redistributed, the clinical picture was similar between the two treatment groups. Importantly, neither PLA nor $0.9 \% \mathrm{NaCl}$ induced significant hyponatremia or hyperkalemia. In fact, the frequency of conversion to abnormal laboratory values was similar between groups.

Although randomization was performed at the center level, the distribution of the children's age and weight

\section{Plasma-Lyte A} $n=39$

Baseline

Hour 4

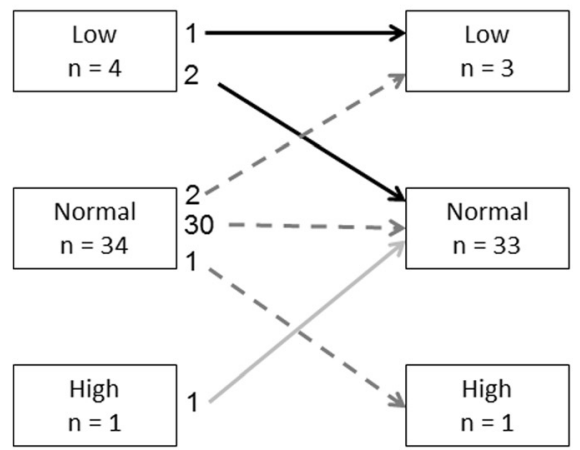

All mITT patients with labvalues are presented.

$\geq 6$ months to $\leq 2$ years of age

Low: $<3.5 \mathrm{mEq} / \mathrm{L}$

Normal: $3.5-5.6 \mathrm{mEq} / \mathrm{L}$

High: $>5.6 \mathrm{mEq} / \mathrm{L}$

$\geq 2$ years of age

Low: $<3.0 \mathrm{mEq} / \mathrm{L}$

Normal. 3.0-5.5 mEq/L

\section{$0.9 \% \mathrm{NaCl}$}

$\mathrm{n}=38$

Baseline

Hour 4

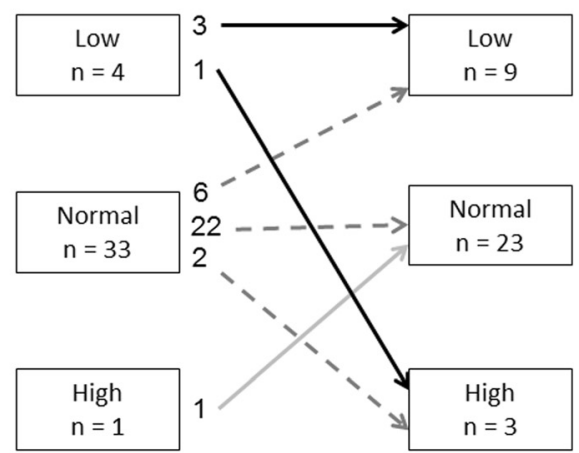

Fig. 3 Change in potassium levels from baseline to hour 4 
was dissimilar between groups, precluding some test comparisons due to small sample size. However, there were no differences in weight-based rehydration volumes or time despite baseline differences in age and capillary refill. Age stratification demonstrated a similar treatment effect across age groups.

We tested serum bicarbonate as the primary outcome of this study based on evidence suggesting that dehydration severity is related to bicarbonate [23]. Low serum bicarbonate levels are the most common electrolyte abnormality occurring in children with AGE, and dehydration severity has been found to be related to the bicarbonate concentration on admission [24, 25]. Bicarbonate is also the electrolyte most likely to alter care [25] in that it correlates with extended stay, admission to the observation unit, and administration of more IVT. Bicarbonate is a quantifiable, objective determinant, thus it is ideal for statistical power determination [9]. The European Society for Paediatric Gastroenterology, Hepatology, and Nutrition/ European Society for Paediatric Infectious Diseases recommends that serum bicarbonate laboratory tests be considered in dehydrated children if IVT is started [26]. These guidelines also recommend rapid rehydration with $20 \mathrm{~mL} / \mathrm{kg} / \mathrm{h}$ of $0.9 \%$ saline solution for 2 to $4 \mathrm{~h}$.

The high level of chloride in $0.9 \% \mathrm{NaCl}$ is known to be associated with hyperchloremic metabolic acidosis. Therefore, it is not surprising that despite its ability to rehydrate in this study, $0.9 \% \mathrm{NaCl}$ did not improve metabolic acidosis. Our study determined that correcting acidosis and fluid status was associated with clinically relevant outcomes of significant improvement in dehydration scores and abdominal pain. In addition, although the study was not powered to detect a difference in time to rehydration, the data suggest that there may be a clinically meaningful difference of nearly $1 \mathrm{~h}(P=.13)$ and may warrant further study with a larger sample.

Interestingly, $0.9 \% \mathrm{NaCl}$ induced hyperchloremia without an associated change in bicarbonate. This finding is in contrast to studies in children with severe AGE [12] where it increased bicarbonate, and in contrast to adult studies that show when $0.9 \% \mathrm{NaCl}$ is used as a resuscitative fluid, it generally decreases serum bicarbonate [27-29].

When $0.9 \% \mathrm{NaCl}$ is used to treat children with acute diarrhea and severe dehydration, $\mathrm{pH}$ may decrease despite improvement in clinical signs of rehydration [30] In the present study the finding that $0.9 \% \mathrm{NaCl}$ caused a significant increase in serum chloride levels suggests that $0.9 \% \mathrm{NaCl}$ may exacerbate AGE acidosis via an ensuing non-anion gap metabolic acidosis, due to a rapid rise in serum chloride levels relative to sodium [29].

The majority of children were rehydrated with approximately $40 \mathrm{~mL} / \mathrm{kg}$ of treatment fluid. Although we allowed treatment for up to $8 \mathrm{~h}$, most were rehydrated with bolus infusions of less than $2 \mathrm{~h}$ and independent of
IVT type, approximately one-third in each group needed observation/inpatient admission for continued hydration.

We also found that electrolyte abnormalities posttreatment were similar between the two treatment groups, alleviating concerns of using a solution that contains a lower sodium concentration than $0.9 \% \mathrm{NaCl}$ and that contains potassium.

While common practice does not introduce potassium until urine output is observed, this study supports the safe use of a fluid containing physiologic amounts of potassium. In fact, the amount of potassium delivered by PLA treatment during the study is surprisingly small-PLA contains $5 \mathrm{mEq} / \mathrm{L}$ of potassium. The average child in the PLA group weighed approximately $16 \mathrm{~kg}$. At $40 \mathrm{~mL} / \mathrm{kg}$, the average child received a total of $3.2 \mathrm{mEq}$ of potassium via PLA, which is equivalent to about one-third of a banana.

The strengths of this study were its randomization, effective blinding, clinical equipoise, and multicenter design. Limitations were its relatively small sample size and the resultant inability to detect some clinically important secondary outcomes. Although the primary objective was achieved despite a lower-than-planned enrollment, not meeting planned enrollment may have impaired our ability to detect some of the secondary outcomes. Moreover, although the random assignment was not similar in terms of age or weight, the weight-based volumes delivered were similar. The planned evaluation of the impact of PLA by severity of baseline acidosis as measured by the bicarbonate strata was limited by the lack of severely dehydrated children in the $0.9 \% \mathrm{NaCl}$ group.

\section{Conclusion}

This study adds new information for the treatment of AGE-induced dehydration. PLA is an appropriate alternative to $0.9 \% \mathrm{NaCl}$ because it provides the necessary water and electrolyte replacement, and as an alkalinizing agent it may ameliorate the clinical sequelae of AGE-induced acidosis. Both PLA and $0.9 \% \mathrm{NaCl}$ were effective and well tolerated and had similar safety profiles. Plasma-Lyte A was more effective than $0.9 \% \mathrm{NaCl}$ at correcting acidosis, in particular in patients with moderate acidosis on admission, and led to improved clinical findings of dehydration.

\section{Additional file}

Additional file 1: Table S1. Ethics Committees. Table S2. IVF bolus during screening and safety follow-up visits (mITT population). (DOCX 15 kb)

\section{Abbreviations}

AGE, Acute gastroenteritis; BARF, Baxter Animated Retching Face; ED, Emergency department; FLACC, Face, legs, activity, cry, consolability pain assessment scale for children; HCA, Hyperchloremic metabolic acidosis; IVT, Intravenous fluid therapy; LR, Lactated Ringer's; mITT, Modified intent-to- 
treat; NaCl, Sodium chloride; PLA, Plasma-Lyte A (sodium chloride, sodium gluconate, sodium acetate, potassium chloride and magnesium chloride

\section{Acknowledgements}

The authors gratefully acknowledge the editorial assistance provided by Ed Shifflett, PhD; and Elizabeth Rosenberg, PhD; of AlphaBioCom, LLC, King of Prussia, PA, which was funded by Baxter Healthcare Corporation. BJS and CRS were employees of Baxter Healthcare Corporation during the study design, completion, and manuscript development.

\section{Funding}

Baxter Healthcare Corporation funded this study.

\section{Availability of data and materials}

Dataset (s) supporting the conclusions of this article are included within the article and are available at clinicaltrials.gov [https://clinicaltrials.gov/ct2/show/ results/NCT01234883?term=plasma-lyte+and+baxter\&rank=4]. Due to privacy and consent, patient-level data are not posted in a public repository. However, proposals for data requests can be sent to Baxter for review.

\section{Authors' contributions}

SLG served as the safety monitor for the study, co-wrote the first draft, and saw and approved the final version of the manuscript. HD was the statistician for the study and saw and approved the final version of the manuscript. CHA co-wrote the first draft; was one of the site principal investigators for the study and contributed to data collection, data review and manuscript writing and revisions; and saw and approved the final version of the manuscript for submission. CRS co-wrote the first draft and saw and approved the final version of the manuscript for submission. BJS co-wrote the first draft and saw and approved the final version of the manuscript for submission. RDG was one of the site principal investigators for the study and contributed to data collection, data review and manuscript writing and revisions; and saw and approved the final version of the manuscript for submission. SB was one of the site principal investigators for the study and contributed to data collection data review and manuscript writing and revisions; and saw and approved the final version of the manuscript for submission. HKS was one of the site principal investigators for the study and contributed to data collection, data review and manuscript writing and revisions; and saw and approved the final version of the manuscript for submission. MHG was one of the site principal investigators for the study and contributed to data collection, data review and manuscript writing and revisions; and saw and approved the final version of the manuscript for submission. PRS was one of the site principal investigators for the study and contributed to data collection, data review and manuscript writing and revisions; and saw and approved the final version of the manuscript for submission. DMS was one of the site principal investigators for the study and contributed to data collection, data review and manuscript writing and revisions; and saw and approved the final version of the manuscript for submission. SEM was one of the site principal investigators for the study and contributed to data collection, data review and manuscript writing and revisions; and saw and approved the final version of the manuscript for submission. DWJ was one of the site principal investigators for the study and contributed to data collection, data review and manuscript writing and revisions; and saw and approved the final version of the manuscript for submission. EAH was one of the site principal investigators for the study and contributed to data collection, data review and manuscript writing and revisions; and saw and approved the final version of the manuscript for submission.

\section{Authors' information}

Not applicable.

\section{Competing interests}

CHA has received industry-funded clinical research from Venaxis, Salter Labs, Cerexa, AstraZeneca, and Baxter. Dr. Simon has received grant funding from Aspen Pharma/Nenaxis Pharma. MHG has received funding as a co-investigator from AHRQ. PRS has received research funding from AspenBioPharma and Baxter. SEM has received research grants from Durata, Shire Orphan Therapies, Aspen Biopharma, Baxter Healthcare, Halozyme, Luitpold Pharmaceuticals, Roche, Ischemia Care, and Gebauer processed through the hospital, Cleveland Clinic Foundation. EAH has received industry funded clinical research from CSL Behring, Baxter, Durata Therapeutics. SLG has received industry funded clinical research from Baxter and Gambro. HD is an employee of Baxter. BJS and CRS were employees of Baxter at the time of this study. DMS, DWJ, RDG and SB declare that they have no competing interests.

\section{Consent for publication}

Not applicable.

\section{Ethics approval and consent to participate}

Institutional ethics approval was obtained from each institution (Additional file 1: Table S1), and written informed consent was obtained from the parent/legal guardian of all children before randomization.

\section{Author details}

'Department of Pediatrics, Dell Medical School at University of Texas at Austin, 4900 Mueller Blvd, Austin, TX 78746, USA. ${ }^{2}$ Department of Pediatrics, British Columbia Children's Hospital, University of British Columbia, Vancouver, BC, Canada. ${ }^{3}$ Department of Pediatrics, Cincinnati Children's Hospital Medical Center, Cincinnati, OH, USA. ${ }^{4}$ Departments of Pediatrics and Emergency Medicine, Emory University/Children's Healthcare of Atlanta, Atlanta, GA, USA. ${ }^{5}$ Pediatric Emergency Medicine, Children's Hospital of Wisconsin, Milwaukee, WI, USA. ${ }^{6}$ Pediatric Emergency Medicine Associates, Children's Healthcare of Atlanta, Atlanta, GA, USA. ${ }^{7}$ Pediatric Emergency Services, Oregon Health and Science University, Portland, OR, USA.

${ }^{8}$ Department of Emergency Medicine, Cleveland Clinic, Cleveland, OH, USA. ${ }^{9}$ Departments of Pediatrics, Pharmacology and Physiology, Alberta Children's Hospital, Calgary, AB, Canada. ${ }^{10}$ Research and Development, Baxter Healthcare Corporation, Deerfield, IL, USA. ${ }^{11}$ Bristol-Myers Squibb, Pennington, NJ, USA.

Received: 26 August 2015 Accepted: 19 July 2016

Published online: 02 August 2016

\section{References}

1. Bruzzese E, Lo Vecchio A, Guarino A. Hospital management of children with acute gastroenteritis. Curr Opin Gastroenterol. 2013;29:23-30.

2. Kilgore A, Donauer S, Edwards KM, Weinberg GA, Payne DC, Szilagyi PG, et al. Rotavirus-associated hospitalization and emergency department costs and rotavirus vaccine program impact. Vaccine. 2013;31:4164-71.

3. Matson DO, Staat MA, Azimi P, Itzler R, Bernstein DI, Ward RL, et al. Burden of rotavirus hospitalisations in young children in three paediatric hospitals in the United States determined by active surveillance compared to standard indirect methods. J Paediatr Child Health. 2012;48:698-704.

4. Wikswo ME, Hall AJ. Outbreaks of acute gastroenteritis transmitted by person-to-person contact-United States, 2009-2010. MMWR Surveill Summ. 2012;61:1-12.

5. Jones TF, McMillian MB, Scallan E, Frenzen PD, Cronquist AB, et al. A population-based estimate of the substantial burden of diarrhoeal disease in the United States; FoodNet, 1996-2003. Epidemiol Infect. 2007;135:293-301.

6. Graves NS. Acute gastroenteritis. Prim Care. 2013;40:727-41.

7. Tate JE, Burton AH, Boschi-Pinto C, Steele AD, Duque J, Parashar UD, et al. 2008 estimate of worldwide rotavirus-associated mortality in children younger than 5 years before the introduction of universal rotavirus vaccination programmes: a systematic review and meta-analysis. Lancet Infect Dis. 2012;12:136-41.

8. Gennari FJ, Weise WJ. Acid-base disturbances in gastrointestinal disease. Clin J Am Soc Nephrol. 2008;3:1861-68.

9. Yilmaz K, Karabocuoglu M, Citak A, Uzel N. Evaluation of laboratory tests in dehydrated children with acute gastroenteritis. J Paediatr Child Health. 2002:38:226-28.

10. Freedman SB, DeGroot JM, Parkin PC. Successful discharge of children with gastroenteritis requiring intravenous rehydration. J Emerg Med. 2014;46:9-20.

11. Neville KA, Verge CF, Rosenberg AR, O'Meara MW, Walker JL. Isotonic is better than hypotonic saline for intravenous rehydration of children with gastroenteritis: a prospective randomised study. Arch Dis Child. 2006;91:226-32.

12. Mahajan V, Sajan SS, Sharma A, Kaur J. Ringers lactate vs Normal saline for children with acute diarrhea and severe dehydration- a double blind randomized controlled trial. Indian Pediatr. 2012;49:963-68.

13. Young JB, Utter GH, Schermer CR, Galante JM, Phan HH, Yang Y, et al. Saline versus Plasma-Lyte $\mathrm{A}$ in initial resuscitation of trauma patients: a randomized trial. Ann Surg. 2014;259:255-62. 
14. McFarlane C, Lee A. A comparison of Plasmalyte 148 and $0.9 \%$ saline for intra-operative fluid replacement. Anaesthesia. 1994;49:779-81.

15. Hadimioglu N, Saadawy I, Saglam T, Ertug Z, Dinckan A. The effect of different crystalloid solutions on acid-base balance and early kidney function after kidney transplantation. Anesth Analg. 2008;107:264-69.

16. Yunos NM, Bellomo R, Hegarty C, Story D, Ho L, Bailey M. Association between a chloride-liberal vs chloride-restrictive intravenous fluid administration strategy and kidney injury in critically ill adults. JAMA. 2012;308:1566-72.

17. Centers for Disease Control and Prevention. Guidelines for Management of Acute Diarrhea: Disaster Safety. 2005. http://emergency.cdc.gov/disasters/ disease/diarrheaguidelines.asp. Accessed 25 July 2016.

18. Fields JM, Dean AJ. Systemic causes of abdominal pain. Emerg Med Clin North Am. 2011;29:195-210.

19. Rosner MH. Metabolic Acidosis in Patients with Gastrointestinal Disorders: Metabolic and Clinical Consequences. Nutrition Issues in Gastroenterology, Series \#73. Practical Gastroenterology. 2009. p. 42-52.

20. Gorelick MH, Shaw KN, Murphy KO. Validity and reliability of clinical signs in the diagnosis of dehydration in children. Pediatrics. 1997;99, E6.

21. World Health Organization. World Health Organization (WHO) Guidelines on Treatment of Diarrhea. 2005. http://www.who.int/maternal_child_ adolescent/documents/9241593180/en/ Accessed September 15, 2014.

22. Baxter AL, Watcha MF, Baxter WV, Leong T, Wyatt MM. Development and validation of a pictorial nausea rating scale for children. Pediatrics. 2011;127:e1542-49.

23. Vega RM, Avner JR. A prospective study of the usefulness of clinical and laboratory parameters for predicting percentage of dehydration in children. Pediatr Emerg Care. 1997;13(3):179-82.

24. Reid SR, Bonadio WA. Outpatient rapid intravenous rehydration to correct dehydration and resolve vomiting in children with acute gastroenteritis. Ann Emerg Med. 1996;28:318-23.

25. Wathen JE, Mackenzie T, Bothner JP. Usefulness of the serum electrolyte panel in the management of pediatric dehydration treated with intravenously administered fluids. Pediatrics. 2004;114:1227-34.

26. Guarino A, Ashkenazi S, Gendrel D, Vecchio AL, Shamir R, Szajewska H. European society for paediatric gastroenterology, hepatology, and nutrition/ European society for paediatric infectious diseases evidence-based guidelines for the management of acute gastroenteritis in children in europe: update 2014. J Pediatr Gastroenterol Nutr. 2014;59:132-52.

27. Eisenhut M. Hyperchloraemic acidosis in patients given rapid isotonic saline infusions. Arch Dis Child. 2007:92:560.

28. Chowdhury AH, Cox EF, Francis ST, Lobo DN. A randomized, controlled, double-blind crossover study on the effects of 2-L infusions of $0.9 \%$ saline and plasma-lyte 148 on renal blood flow velocity and renal cortical tissue perfusion in healthy volunteers. Ann Surg. 2012;256:18-24.

29. Reid F, Lobo DN, Williams RN, Rowlands BJ, Allison SP. (Ab) normal saline and physiological Hartmann's solution: a randomized double-blind crossover study. Clin Sci (Lond). 2003;104:17-24.

30. Juca CA, Rey LC, Martins CV. Comparison between normal saline and a polyelectrolyte solution for fluid resuscitation in severely dehydrated infants with acute diarrhoea. Ann Trop Paediatr. 2005:25:253-60.

\section{Submit your next manuscript to BioMed Central and we will help you at every step:}

- We accept pre-submission inquiries

- Our selector tool helps you to find the most relevant journal

- We provide round the clock customer support

- Convenient online submission

- Thorough peer review

- Inclusion in PubMed and all major indexing services

- Maximum visibility for your research

Submit your manuscript at www.biomedcentral.com/submit

) Biomed Central 